\title{
Cross-Linked Polyethylene Glycol Beads to Separate 99mTc-Pertechnetate from Low-Specific-Activity Molybdenum
}

\author{
François Bénard ${ }^{1,2}$, Stefan K. Zeisler ${ }^{3}$, Milan Vuckovic ${ }^{1}$, Kuo-Shyan Lin $^{1,2}$, Zhengxing Zhang ${ }^{1}$, Nadine Colpo ${ }^{1}$, \\ Xinchi Hou ${ }^{4}$, Thomas J. Ruth ${ }^{1,3}$, and Paul Schaffer ${ }^{2,3}$ \\ ${ }^{1}$ BC Cancer Agency, Vancouver, British Columbia, Canada; ${ }^{2}$ Department of Radiology, University of British Columbia, Vancouver, \\ British Columbia, Canada; ${ }^{3}$ TRIUMF, Vancouver, British Columbia, Canada; and ${ }^{4}$ Department of Physics and Astronomy, University \\ of British Columbia, Vancouver, British Columbia, Canada
}

We report a kit-based approach for the purification of sodium pertechnetate $\left({ }^{99 \mathrm{~m}_{\mathrm{CO}}}{ }_{4}^{-}\right)$from solutions with high $\mathrm{MoO}_{4}{ }^{2-}$ content. Methods: Cross-linked polyethylene glycol resins (ChemMatrix) were used to separate ${ }^{99 \mathrm{~m} T c}$ and molybdenum in $4 \mathrm{~N} \mathrm{NaOH}$. The resins were loaded at various flow rates and eluted with water to

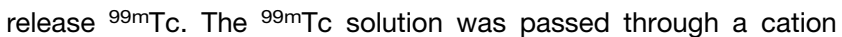
exchange resin and an alumina cartridge, followed by saline elution. This process was tested with cyclotron-produced ${ }^{99 m T c}$ using an automated system and disposable kits. Results: Optimal results were obtained by loading $500 \mathrm{mg}$ of resin at flow rates of up to $3.1 \mathrm{~mL} / \mathrm{min}$, with quantitative extraction of $99 \mathrm{mTc}$ from the molybdate solution and complete release of ${ }^{99 \mathrm{mTc}}$ after elution with water. The automated system was highly efficient at isolating $\mathrm{Na}^{99 m} \mathrm{TcO}_{4}$ within minutes, with a recovery rate of $92.7 \% \pm 1.1 \%$ (mean $\pm \mathrm{SD}$ ) using cyclotron-produced ${ }^{99 \mathrm{mT}}$. Conclusion: ChemMatrix resins were highly effective at separating ${ }^{99 \mathrm{~m}_{\mathrm{TCO}}}{ }_{4}{ }^{-}$from molybdate solutions.

Key Words: 99mTc-pertechnetate; molybdenum; generators

J Nucl Med 2014; 55:1910-1914

DOI: 10.2967/jnumed.114.143834

$\mathbf{T}$ he radioisotope ${ }^{99 \mathrm{~m}} \mathrm{Tc}$ is typically obtained from ${ }^{99} \mathrm{Mo} /{ }^{99 \mathrm{~m}} \mathrm{Tc}$ generators made with a small alumina cartridge on which radioactive ${ }^{99} \mathrm{Mo}$ is immobilized as ${ }^{99} \mathrm{MoO}_{4}{ }^{2-}$. High-specific-activity ${ }^{99} \mathrm{Mo}$ is required because of the limited binding capacity of alumina $(1,2)$. However, most research reactors used for radioisotope production are facing obsolescence, and supply disruptions have become more common. Alternative production methods have been proposed to secure the supply of ${ }^{99 \mathrm{~m}} \mathrm{Tc}$, such as direct production by cyclotrons (3) and production of ${ }^{99} \mathrm{Mo}$ by linear accelerators or neutron enrichment of ${ }^{98} \mathrm{Mo}$ (4). These approaches lead to high amounts of molybdenum present in the final target dissolution mixture.

The use of biphasic separation was reported for the extraction of ${ }^{99} \mathrm{Tc}$ from nuclear waste eluents (5) and later was implemented in a generator system (6). This approach used polyethylene glycol (PEG) chains grafted onto polystyrene particles to enable separa-

Received May 27, 2014; revision accepted Sep. 17, 2014.

For correspondence or reprints contact: François Bénard, BC Cancer Agency, 675 W. 10th Ave., Vancouver, BC, Canada V5Z 1L3.

E-mail: fbenard@bccrc.ca

Published online Oct. 20, 2014.

COPYRIGHT (c) 2014 by the Society of Nuclear Medicine and Molecular Imaging, Inc. tion on solid support. We recently reported a similar approach for the purification of cyclotron-produced ${ }^{99 \mathrm{~m}} \mathrm{Tc}(7)$.

PEG-grafted polystyrene resins have long been used for the solidphase synthesis of lengthy, difficult peptides. To overcome some limitations of polystyrene-based resins, cross-linked PEG-only resins were developed for solid-phase peptide synthesis (8). These resins are reported to have high loading capacity, high swelling, broad solvent compatibility, and chemical resistance. Because these beads maintain a high number of PEG sites, we hypothesized that this material would be effective for separating ${ }^{99} \mathrm{mc}$ from ${ }^{99} \mathrm{MoO}_{4}{ }^{2-}$ on the basis of the established propensity for ${ }^{99} \mathrm{mcO}_{4}{ }^{-}$to favorably associate with PEG moieties under high dielectric potential (9).

\section{MATERIALS AND METHODS}

\section{PEG-Only Resins}

A series of cross-linked PEG resins, originally developed for solidphase synthesis of long peptides, was used for this project. All were based on ChemMatrix resins (PCAS Biomatrix). Aminomethyl and Wang (p-alkoxybenzyl alcohol) resins were purchased from the manufacturer. Nitrile resins were obtained from PCAS Biomatrix as research samples and were also available as a special order from the supplier.

The structures of resins are shown in Figure 1, with aminomethylChemMatrix as structure 1 . The acetyl resin (structure 2) was prepared by incubating aminomethyl resin $(1.68 \mathrm{~g})$ with 10 equivalents of acetic anhydride and 10 equivalents of $N, N$-diisopropylethylamine in methylene chloride $(30 \mathrm{~mL})$ at ambient temperature for $48 \mathrm{~h}$. The mesyl resin was synthesized by reacting $2.0 \mathrm{~g}$ of structure 1 with 5 equivalents of methane sulfonyl chloride and 5 equivalents of $N, N$-diisopropylethylamine in methylene chloride $(60 \mathrm{~mL})$ at ambient temperature for $4 \mathrm{~d}$ to obtain derivative 3. tert-butyloxycarbonyl (BOC)-ChemMatrix was prepared by reacting $1(2.0 \mathrm{~g})$ with 5 equivalents of di-tert-butyl dicarbonate and 5 equivalents of $N, N$-diisopropylethylamine in methanol $(60 \mathrm{~mL})$ at ambient temperature for $4 \mathrm{~d}$ to obtain structure 4. PEGylated ChemMatrix was prepared by reacting $1.5 \mathrm{~g}$ of structure 1 with poly (ethylene glycol) methyl ether tosylate (average molecular weight, $2,000)$ and 2 equivalents of potassium carbonate in acetonitrile $(30 \mathrm{~mL})$ under reflux for $6 \mathrm{~d}$. After dilution of the reaction mixture with water $(30 \mathrm{~mL})$, the PEG-ChemMatrix resin (derivative 5) was recovered.

All resins were recovered by filtration, washed twice with $20 \mathrm{~mL}$ of $\mathrm{N}$-methylpyrrolidinone, methanol, and $\mathrm{N}$-methylpyrrolidinone followed by $3 \times 20 \mathrm{~mL}$ of methylene chloride and methanol and then dried under a vacuum before use.

\section{Optimization of Separation Conditions}

The ${ }^{99 \mathrm{~m}} \mathrm{Tc} /$ molybdate separation conditions were established to replicate the composition of an irradiated ${ }^{100} \mathrm{Mo}$ cyclotron target. Briefly, $1.5-$ $2.0 \mathrm{~g}$ of molybdenum metal powder were dissolved in $20 \mathrm{~mL}$ of $30 \%$ 


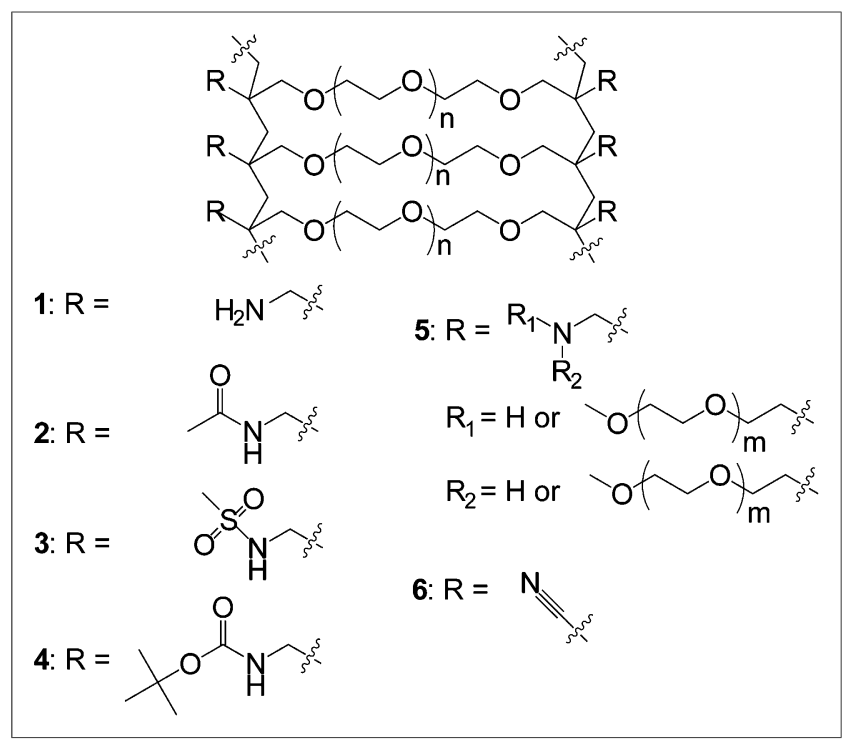

FIGURE 1. Structures of various ChemMatrix resins tested for ${ }^{99 m \mathrm{Tc}}$ purification. Structure $\mathbf{1}$ is aminomethyl-ChemMatrix, structure $\mathbf{2}$ is acetyl-ChemMatrix, structure $\mathbf{3}$ is mesyl-ChemMatrix, structure $\mathbf{4}$ is BOC-ChemMatrix, structure 5 is PEG-ChemMatrix, and structure 6 is nitrile-ChemMatrix.

$\mathrm{H}_{2} \mathrm{O}_{2}$, ${ }^{99} \mathrm{~m} \mathrm{Tc}$ was added to the solution, and $8 \mathrm{M} \mathrm{NaOH}$ was added slowly to obtain a mixture of ${ }^{99 \mathrm{~m}} \mathrm{Tc}$ and molybdenum oxides in a final concentration of $4 \mathrm{~N} \mathrm{NaOH}$. The resins were loaded using a syringe pump (Harvard Apparatus) at flow rates from 0.5 to $2.0 \mathrm{~mL} / \mathrm{min}$. The resins were eluted with distilled, deionized water at flow rates ranging from 0.5 to $10 \mathrm{~mL} / \mathrm{min}$ to release ${ }^{99 \mathrm{~m}} \mathrm{Tc}$. The activity was assayed in a vial before loading on resin, after trapping on resin, and after elution with water. The loading percentage was calculated as the activity on resin divided by the total activity (waste + resin). The elution percentage was calculated as the percentage activity recovered divided by the total activity (eluent + resin). The total net percentage yield was calculated as the activity recovered divided by the total activity (waste + resin + eluent).

\section{Disposable Kits for Automated Purification}

This purification process was implemented for cyclotron production of ${ }^{99 \mathrm{~m}} \mathrm{Tc}$ on a compact commercial automated synthesizer, which uses disposable kits (miniAIO; Trasis). The kits were constituted of U.S. Pharmacopeia grade VI plastics, with 1/16-in (1.6-mm)-diameter silicon tubing (Tygon), polypropylene barbed connectors, and Luer adapters, as well as standard disposable syringes. A 4-mL solid-phase separation reservoir with a frit at the bottom (United Chemical Technologies) was used to hold the resin. A strong cation exchange resin (OnGuard II H Cartridge; Dionex) was used to neutralize the solution eluted from the ChemMatrix resin. An alumina cartridge (Sep-Pak Alumina A Plus Light Cartridge; Waters) was used to remove potential traces of molybdenum and trap ${ }^{99 \mathrm{~m}} \mathrm{Tc}$ for dispensing into $0.9 \%$ sodium chloride solution. A photograph of a disposable kit assembled on the automated synthesis unit is shown in Figure 2.

\section{Procedure for ${ }^{99 m}$ Tc Automated Purification}

${ }^{99 \mathrm{~m}} \mathrm{Tc}$ was separated using a modification of aqueous biphasic extraction procedures reported elsewhere (7). The process flow is illustrated in Figure 3. Briefly, the ChemMatrix resin was preconditioned with $5 \mathrm{~mL}$ of $4 \mathrm{~N} \mathrm{NaOH}$. The cation exchange resin and alumina cartridges were rinsed and preconditioned with $3 \mathrm{~mL}$ of water. The ${ }^{99 \mathrm{~m}} \mathrm{Tc} /$ molybdate crude dissolution mixture $(75 \mathrm{~mL})$ in $4 \mathrm{~N} \mathrm{NaOH}$ was loaded at flow rates of $2.6-3.1 \mathrm{~mL} / \mathrm{min}$ onto the resin. During this step, all the liquid that passed through the resin went to a waste vial, to

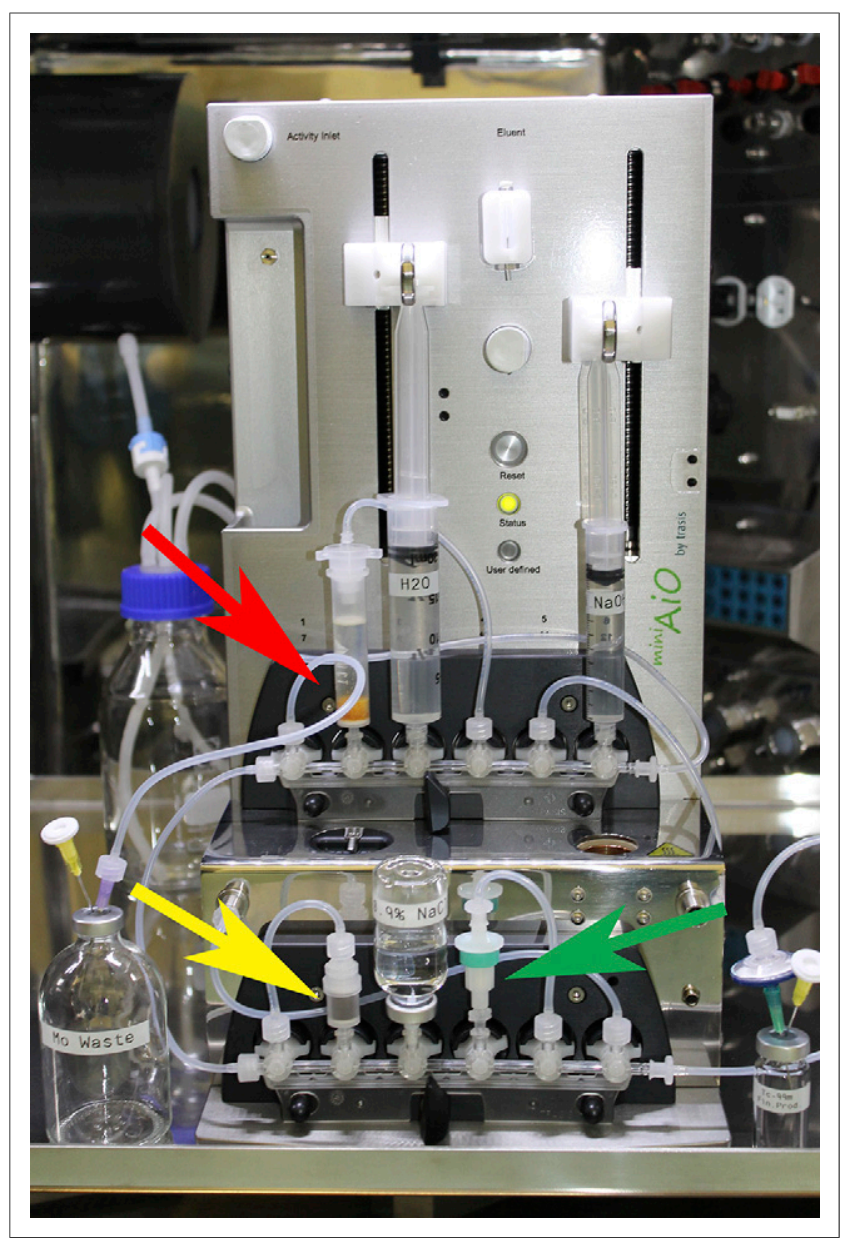

FIGURE 2. Picture of automated synthesis unit equipped with disposable kit for purification of ${ }^{99 \mathrm{mTc}} \mathrm{Tc}$ pertechnetate. The 2 syringes at top are initially filled with water $\left(\mathrm{H}_{2} \mathrm{O}\right)$ and $4 \mathrm{~N}$ sodium hydroxide $(\mathrm{NaOH})$. ChemMatrix resin is indicated with red arrow. Cation exchange resin is indicated with yellow arrow. Alumina cartridge location is indicated with green arrow.

recover molybdenum for recycling or reuse. The resin was washed with $4 \mathrm{~mL}$ of $4 \mathrm{~N} \mathrm{NaOH}$, purged with nitrogen gas, and eluted with $10 \mathrm{~mL}$ of water at a rate of $2 \mathrm{~mL} / \mathrm{min}$. The eluent was passed through the cation exchange resin and the alumina columns connected in series.

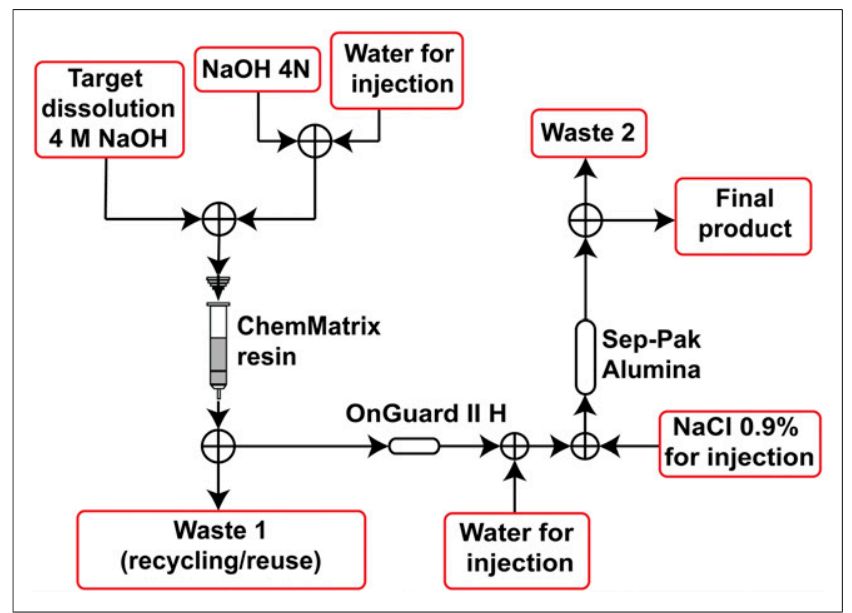

FIGURE 3. Diagram summarizing automated purification process. 


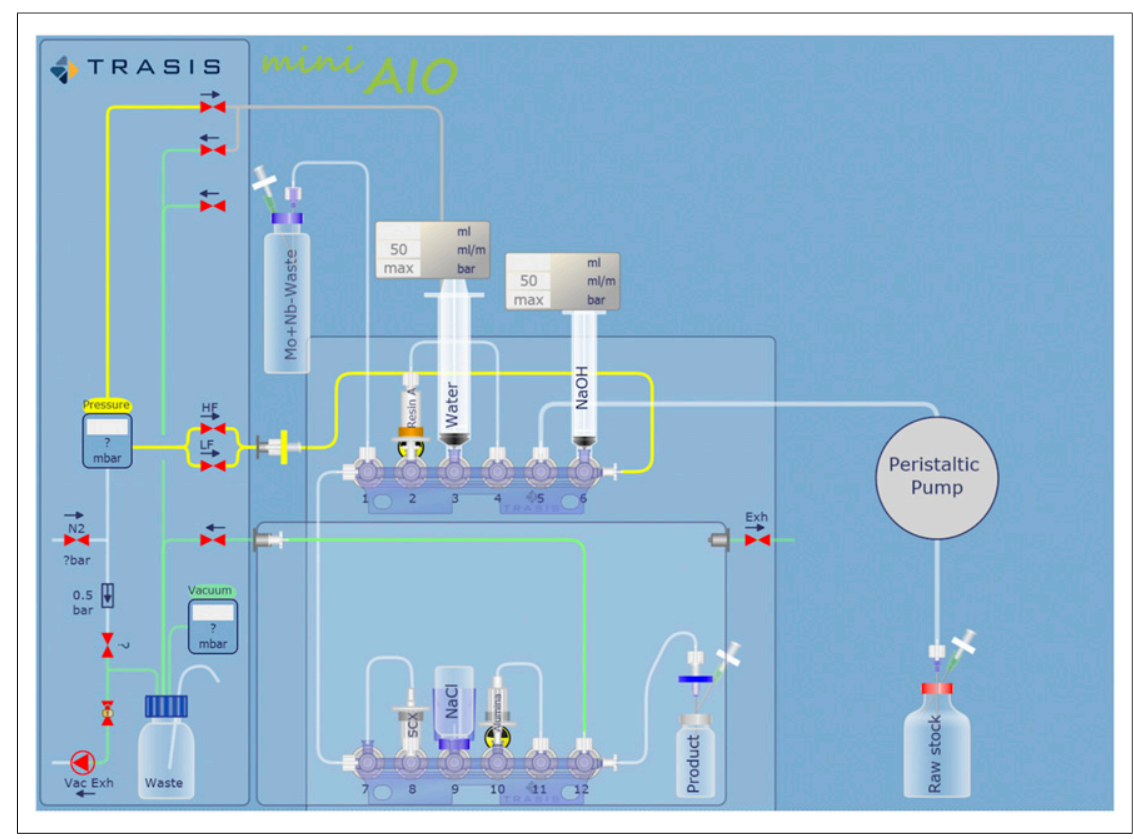

FIGURE 4. Screen capture of user-defined layout of control screen, at start of purification process, highlighting relationship of various rotary actuators and syringes operating disposable kit components (adapted from Trasis base layout).

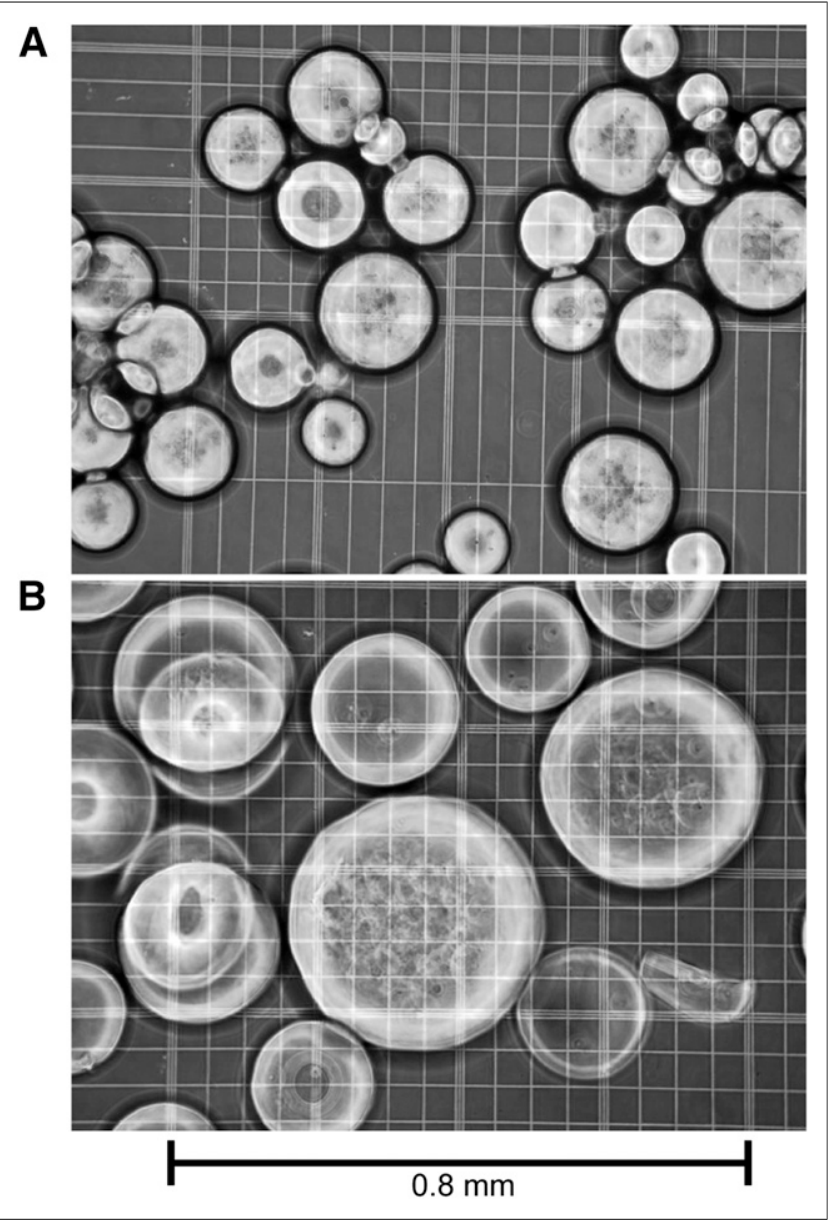

FIGURE 5. Microscopic images of ChemMatrix resin loaded on hemocytometer. Beads are significantly smaller in high-salt solutions such as $4 \mathrm{M} \mathrm{NaOH}(\mathrm{A})$ than in water (B).
The cartridges were rinsed with water, and the alumina column was eluted with $10 \mathrm{~mL}$ of normal saline through a $0.22-\mu \mathrm{m}$ sterile filter (Millex-GS; Millipore) for recovery of $\mathrm{Na}^{99} \mathrm{TcO}_{4}$ into a final product vial. The process was completed in $41-46 \mathrm{~min}$. A screen capture of the control software is shown in Figure 4.

\section{Testing Using \\ Cyclotron-Produced ${ }^{99 m}$ Tc}

Three ${ }^{99 \mathrm{~m}} \mathrm{Tc}$ production runs were performed following procedures previously described (10), with an irradiation time of $1-1.5 \mathrm{~h}$ at a beam current of $100 \mu \mathrm{A}$. The targets were dissolved in $10 \% \mathrm{H}_{2} \mathrm{O}_{2}$. ${ }^{99 \mathrm{~m}} \mathrm{Tc}$-pertechnetate was purified using the automated system described above.

\section{Quality Control and Kit Radiolabeling}

The $\mathrm{Na}^{99} \mathrm{TcO}_{4}$ solution was tested for alumina by a colorimetric test kit (Biodex). Hydrolyzed reduced ${ }^{99 \mathrm{~m}} \mathrm{Tc}$ was evaluated by thin-layer paper chromatography using Whatman paper, developed in acetone. Kits for neutral ( ${ }^{99 m} \mathrm{Tc}-$ exametazime; GE Healthcare), cationic ( ${ }^{99 \mathrm{~m}} \mathrm{Tc}$-tetrofosmin; GE Healthcare), and anionic ( ${ }^{99 \mathrm{~m}} \mathrm{Tc}-$ medronate; DraxImage) radiopharmaceuticals were reconstituted and tested according to the manufacturer's instructions.

\section{Determination of Radionuclidic Purity}

Radionuclidic purity of the final product was measured on a highpurity germanium $\gamma$-ray spectrometer (Canberra), calibrated using a multinuclide National Institute of Standards and Technology traceable radioactive standard (Eckert and Ziegler). When necessary, radioactive samples were diluted to ensure that detector dead time was less than $5 \%$. All samples used the same geometry as the multinuclide standard source. Measurements of the final product after end-of-beam were taken at 3 and $24 \mathrm{~h}$, at 6-7 d, and in some cases after $30 \mathrm{~d}$. Measurements of the waste vials were taken 4-6 h after end-of-beam.

\section{RESULTS}

We observed significant differences in the volume of the ChemMatrix resins in $4 \mathrm{~N} \mathrm{NaOH}$ compared with water. In $4 \mathrm{~N} \mathrm{NaOH}$, the individual beads were smaller, and particle size increased 2- or 3-fold in water (Fig. 5).

The results of the separation experiments are shown in Table 1. Incomplete trapping was noted with the aminomethyl and acetyl ChemMatrix resins when $300 \mathrm{mg}$ were used at flow rates of $1 \mathrm{~mL} / \mathrm{min}$ or higher. Increasing the quantity of resin to $500 \mathrm{mg}$ led to nearquantitative (97\%-100\%) trapping of ${ }^{99 \mathrm{~m}} \mathrm{Tc}$ with all resins, while allowing higher flow rates. Although adequate release was observed when $300 \mathrm{mg}$ of aminomethyl resin were used, elution was less efficient (69\%-85\%) when higher quantities (>500 mg) of resin were used. All resins with other terminal groups, such as mesyl, acetyl, BOC, Wang, or nitrile, were effective at trapping and releasing ${ }^{99 \mathrm{~m}} \mathrm{Tc}$, with complete or nearly complete trapping and elution.

The automated system with disposable cassettes was highly efficient at isolating cyclotron-produced ${ }^{99 \mathrm{~m}} \mathrm{Tc}$ within minutes, with a recovery rate of $92.7 \% \pm 1.1 \%$ (mean $\pm \mathrm{SD}$; range, $91.5 \%-93.5 \%$ ). Minimal losses occurred, with some ${ }^{99 \mathrm{~m}} \mathrm{Tc}$ being recovered in 
TABLE 1

Results of Separation Experiments

\begin{tabular}{|c|c|c|c|c|c|}
\hline Resin & Mass (mg) & Load (mL/min) & Elution (mL/min) & Load (\%) & Elution (\%) \\
\hline Aminomethyl-ChemMatrix & 200 & 1 & 1 & 86 & 85 \\
\hline Aminomethyl-ChemMatrix & 300 & 0.5 & 0.5 & 100 & 97 \\
\hline Aminomethyl-ChemMatrix & 300 & 1 & 2 & 88 & 96 \\
\hline Aminomethyl-ChemMatrix & 300 & 0.75 & 2 & 88 & 97 \\
\hline Aminomethyl-ChemMatrix & 300 & 0.5 & 5 & 100 & 94 \\
\hline Aminomethyl-ChemMatrix & 600 & 1 & 1 & 100 & 85 \\
\hline Aminomethyl-ChemMatrix & 600 & 2 & 10 & 97 & 69 \\
\hline Aminomethyl-ChemMatrix & 600 & 2 & 1 & 99 & 77 \\
\hline Acetyl-ChemMatrix & 600 & 2 & 1 & 100 & 95 \\
\hline Acetyl-ChemMatrix & 300 & 2 & 2 & 54 & 100 \\
\hline Acetyl-ChemMatrix & 500 & 2 & 2 & 99 & 98 \\
\hline PEG-ChemMatrix & 500 & 2 & 2 & 97 & 98 \\
\hline Mesyl-ChemMatrix & 500 & 2 & 2 & 100 & 100 \\
\hline BOC-ChemMatrix & 500 & 2 & 2 & 100 & 98 \\
\hline Wang-ChemMatrix & 500 & 2 & 2 & 100 & 100 \\
\hline Nitrile-ChemMatrix & 500 & 2 & 2 & 100 & 100 \\
\hline
\end{tabular}

waste $(6.6 \% \pm 1.1 \%)$ or trapped on the resin $(0.19 \% \pm 0.02 \%)$, the alumina cartridge $(0.59 \% \pm 0.12 \%)$, or the cation exchange resin $(0.014 \% \pm 0.003 \%)$. Less than $1 \%$ of the initial activity remained in disposable syringes or lines used in the purification module. No aluminum was detected in the final product. All reconstituted kits passed quality control tests recommended by the manufacturer (Table 2). Decay-corrected to end-of-beam, the radionuclidic purity was $99.940 \% \pm 0.004 \%$ (average percentage of total purified activity with $\mathrm{SD} ; n=3$ production runs). Only traces of other technetium radioisotopes $\left({ }^{97 \mathrm{~m}} \mathrm{Tc}, 0.003 \% \pm 0.004 \%\right.$;
${ }^{96 \mathrm{~g}} \mathrm{Tc}, 0.002 \% \pm 0.001 \% ;{ }^{95 \mathrm{~m}} \mathrm{Tc},<0.0001 \% ;{ }^{95 \mathrm{~g}} \mathrm{Tc}, 0.009 \% \pm 0.005 \%$; ${ }^{94 \mathrm{~m}} \mathrm{Tc}, 0.044 \% \pm 0.012 \% ;{ }^{94 \mathrm{~g}} \mathrm{Tc}, 0.012 \% \pm 0.004 \% ;{ }^{93 \mathrm{~g}} \mathrm{Tc}$, $0.007 \% \pm 0.004 \%$ ) were present in the ${ }^{99 \mathrm{~m} T c-p e r t e c h n e t a t e . ~ O t h e r ~}$ radioactive species known to be coproduced during proton irradiation of ${ }^{100} \mathrm{Mo}(7,11)$, notably radioactive niobium and molybdenum radioisotopes, were not detected in the final product samples but were found in the waste recovery vessel. These radioisotopes included ${ }^{99} \mathrm{Mo}(0.78 \% \pm 0.42 \%$; average percentage of total activity produced with $\mathrm{SD} ; n=3$ production runs), ${ }^{96} \mathrm{Nb}(0.06 \% \pm 0.03 \%)$, and ${ }^{97} \mathrm{Nb}(4.0 \% \pm 2.9 \%)$.

TABLE 2

Results of Quality Control Testing

\begin{tabular}{lccc}
\hline Radiopharmaceutical & Reconstituted activity $(\mathrm{MBq})$ & Radiochemical purity (\%) & Alumina test \\
\hline 99mTc-pertechnetate & $44,363^{*}$ & 98.9 & Negative \\
\hline 99mTc-pertechnetate & $25,887^{*}$ & 99.0 & Negative \\
\hline 99mTc-pertechnetate & $40,959^{*}$ & 98.9 & Negative \\
\hline 99mTc-medronate & 18,500 & 93.3 & - \\
\hline 99mTc-medronate & 8,880 & 97.7 & - \\
99mTc-medronate & 12,950 & 97.3 & - \\
99mTc-exametazime & 2,000 & 81.8 & - \\
\hline 99mTc-exametazime & 1,591 & 84.0 & - \\
99mTc-exametazime & 1,621 & 85.3 & - \\
99mTc-tetrofosmin & 8,800 & 96.3 & - \\
99mTc-tetrofosmin & 5,550 & 97.3 & - \\
99mTc-tetrofosmin & 6,660 & 93.0 & -
\end{tabular}

`Total activity produced. 


\section{DISCUSSION}

Methods developed to separate ${ }^{99 \mathrm{~m}} \mathrm{Tc}$ from ${ }^{99} \mathrm{Mo}$ were recently reviewed by Dash et al. (12). In this study, we showed that ChemMatrix resins were efficient at selectively trapping ${ }^{99 \mathrm{~m}} \mathrm{Tc}$ without retaining molybdenum in the presence of $4 \mathrm{~N} \mathrm{NaOH}$, with quantitative elution using water. The overall $\mathrm{Na}^{99 \mathrm{~m}} \mathrm{TcO}_{4}$ purification was implemented using a compact commercial automated synthesis system designed for use with disposable kits. We achieved high trapping efficiency with reproducible results using cyclotron-produced ${ }^{99 \mathrm{~m}} \mathrm{Tc}$. It should be noted that as the counts in the waste solution were not corrected for the presence of isotope contaminants that are known to occur with cyclotron-produced technetium (such as ${ }^{99} \mathrm{Mo}$ and ${ }^{95} \mathrm{Nb}$ ) and were effectively separated from ${ }^{99 \mathrm{~m}} \mathrm{Tc}$, the recovery percentage of ${ }^{99 \mathrm{~m}} \mathrm{Tc}$ was likely slightly underestimated. Because of the experimental design using cyclotron-produced pertechnetate, we did not evaluate the fraction of molybdenum recovered in the waste vial after technetium extraction by the ChemMatrix resin. Although molybdenum is not retained in high-pH, high-salt solutions by biphasic exchange chromatography, the determination of precise recovery yields will require further studies by testing this system with low-specificactivity ${ }^{99}$ Mo solutions that are quantified before and after purification.

The entire process is amenable to meeting good manufacturing practice-compliant production. This method is applicable for separation of ${ }^{99} \mathrm{mcO}_{4}{ }^{-}$from any solution containing excess molybdate ions and should be suitable for use with low-specific-activity ${ }^{99} \mathrm{Mo}$, with minor modifications to recirculate the ${ }^{99} \mathrm{Mo}$ solution for daily reuse.

\section{CONCLUSION}

Cross-linked PEG beads were highly effective at separating and purifying ${ }^{99 \mathrm{~m}} \mathrm{Tc}$ from low-specific-activity molybdate solutions, with quantitative trapping and elution of ${ }^{99 \mathrm{~m} T c}$. ${ }^{99 \mathrm{~m}} \mathrm{Tc}$-pertechnetate was purified in high yields using a simple disposable kit system.

\section{DISCLOSURE}

The costs of publication of this article were defrayed in part by the payment of page charges. Therefore, and solely to indicate this fact, this article is hereby marked "advertisement" in accordance with 18 USC section 1734. This work was supported by the Natural Sciences and Engineering Research Council, the Canadian Institutes of Health Research, and Natural Resources Canada. A provisional application for a patent was filed for some of the material presented in this article. No other potential conflict of interest relevant to this article was reported.

\section{REFERENCES}

1. Asif M, Mushtaq A. Evaluation of highly loaded low specific activity Mo-99 on alumina column as Tc-99m generator. J Radioanal Nucl Chem. 2010;284:439-442.

2. Chattopadhyay S, Das SS, Das MK, Goomer NC. Recovery of ${ }^{99 \mathrm{~m} T \mathrm{Tc} \text { from }}$ $\mathrm{Na}_{2}\left[{ }^{99} \mathrm{Mo}^{-\mathrm{MoO}_{4}}\right.$ solution obtained from reactor-produced (n,gamma) ${ }^{99} \mathrm{Mo}$ using a tiny Dowex-1 column in tandem with a small alumina column. Appl Radiat Isot. 2008;66:1814-1817.

3. Beaver JE, Hupf HB. Production of ${ }^{99 \mathrm{~m}} \mathrm{Tc}$ on a medical cyclotron: a feasibility study. J Nucl Med. 1971;12:739-741.

4. Pillai MR, Dash A, Knapp FF Jr. Sustained availability of ${ }^{99 \mathrm{~m}} \mathrm{Tc}$ : possible paths forward. J Nucl Med. 2013;54:313-323.

5. Rogers RD, Zhang J. Effects of increasing polymer hydrophobicity on distribution ratios of $\mathrm{TcO}_{4}^{-}$in polyethylene/poly(propylene glycol)-based aqueous biphasic systems. J Chromatogr B Biomed Appl. 1996;680:231-236.

6. McAlister DR, Philip Horwitz E. Automated two column generator systems for medical radionuclides. Appl Radiat Isot. 2009;67:1985-1991.

7. Morley TJ, Dodd M, Gagnon K, et al. An automated module for the separation and purification of cyclotron-produced ${ }^{99} \mathrm{TcO}_{4}$. Nucl Med Biol. 2012;39:551-559.

8. García-Martin F, Quintanar-Audelo M, Garcia-Ramos Y, et al. ChemMatrix, a poly(ethylene glycol)-based support for the solid-phase synthesis of complex peptides. J Comb Chem. 2006;8:213-220.

9. Huddleston J, Griffin S, Zhang J, Willauer H, Rogers R. Metal ion separations in aqueous biphasic systems and with ABEC resins. In: Hatti-Kaul R, ed. Aqueous TwoPhase Systems: Methods and Protocols. Totowa, NJ: Humana Press; 2000:77-94.

10. Bénard F, Buckley KR, Ruth TJ, et al. Implementation of multi-curie production of ${ }^{99 \mathrm{~m}} \mathrm{Tc}$ by conventional medical cyclotrons. J Nucl Med. 2014;55:1017-1022.

11. Celler A, Hou X, Benard F, Ruth T. Theoretical modeling of yields for protoninduced reactions on natural and enriched molybdenum targets. Phys Med Biol. 2011;56:5469-5484.

12. Dash A, Knapp FF Jr, Pillai MR. ${ }^{99} \mathrm{Mo} /{ }^{99} \mathrm{mTc}$ separation: an assessment of technology options. Nucl Med Biol. 2013;40:167-176.

\section{Erratum}

In the article "Preclinical Evaluation of 3-18F-Fluoro-2,2-Dimethylpropionic Acid as an Imaging Agent for Tumor Detection," by Witney et al. (J Nucl Med. 2014;55:1506-1512), reference to part D of Figure 1 is missing from the legend. The legend for part D is as follows: "(D) Effect of exogenous ${ }^{19} \mathrm{~F}$-FPIA and ${ }^{19} \mathrm{~F}-\mathrm{FAC}$ on intracellular metabolite concentrations of acyl-carnitine esters as analyzed by liquid chromatography-mass spectrometry $(n=4)$." We regret the error. 